\title{
SIMPLE ALGORITHMS FOR CALCULATION OF THE AXIAL-SYMMETRIC HEAT TRANSPORT PROBLEM IN A CYLINDER
}

\author{
H. KALIS ${ }^{1}$, A. LASIS ${ }^{2}$ \\ ${ }^{1}$ Institute of Mathematics Latvian Academy of Sciences and University of \\ Latvia \\ Akadēmijas laukums 1, Rīga, LV-1524, Latvia \\ ${ }^{2}$ University of Latvia, Faculty of Physics and Mathematics \\ Zellu str. 8, Rīga, LV-1002, Latvia \\ E-mail: kalis@lanet.lv andrew@simss.lv
}

Received October 1, 2001; revised November 6, 2001

\begin{abstract}
The approximation of axial-symmetric heat transport problem in a cylinder is based on the finite volume method. In the classical formulation of the finite volume method it is assumed that the flux terms in the control volume are approximated with the finite difference expressions. Then in the 1-D case the corresponding finite difference scheme for the given source function is not exact. There we propose the exact difference scheme. In 2$\mathrm{D}$ case the corresponding integrals are approximated using different quadrature formulae. This procedure allows one to reduce the heat transport problem described by a partial differential equation to an initial-value problem for a system of two ordinary differential equations of the order depending on the quadrature formulae used. Numerical solutions of the corresponding algorithms are obtained using MAPLE routines for stiff system of ordinary differential equations.
\end{abstract}

\section{THE MATHEMATICAL MODEL}

The model we consider in this article is the homogenous infinitely long cylinder with the radius $l$. We consider the following dimensionless initial-boundary problem for the temperature $T(t, r)$ distribution in the cylinder in the following form:

$$
\frac{\partial T}{\partial t}=\frac{1}{r} \frac{\partial}{\partial r}\left(r \frac{\partial T}{\partial r}\right)+F(T), \quad r \in(0, l), t>0
$$




$$
\begin{gathered}
\frac{\partial^{2 n-1} T_{1}}{\partial r^{2 n-1}}=0, \quad n \in \mathbb{N}, \\
\frac{\partial T_{2}}{\partial r}=f_{2}\left(T_{2}\right), \\
T(0, r)=T_{0}(r), \quad r \in[0, l],
\end{gathered}
$$

where $\mathrm{T}(\mathrm{t}, \mathrm{r})$ is the dimensionless temperature distribution in the cylinder, $F(T)$ is a nonlinear function, for example, nonlinear heat source arising from chemical reactions, $T_{0}(r)$ is the dimensionless initial temperature, and we denote $T_{1}(t)=T(t, 0), T_{2}(t)=T(t, l)$.

The nonlinear function $f_{2}(T)$ in the boundary condition (1.3) describes the radiation from heaters and convection, as an example,

$$
f_{2}\left(T_{2}\right)=B i_{2}\left(\theta_{h}^{4}-T_{2}^{4}\right)+B_{2}\left(\theta_{a}-T_{2}\right),
$$

where $B_{2}, B i_{2}$ are Biot numbers, $\theta_{h}$ is the dimensionless temperature of heaters, $\theta_{a}$ is the dimensionless temperature of air. The boundary condition (1.2) describes the axial symmetry of the problem.

Note that the equation (1.1) when $r \rightarrow 0$ turns to the heat transfer equation in the Cartesian coordinate system

$$
\frac{\partial T}{\partial t}=2 \frac{\partial^{2} T}{\partial r^{2}}+F(T)
$$

The initial temperature distribution (1.4) is consistent with the boundary conditions (1.2)- (1.3) in the form

$$
\left\{\begin{array}{l}
T_{0}^{\prime}(0)=0 \\
T_{0}^{\prime}(l)=f_{2}\left(T_{2}(0)\right)
\end{array} .\right.
$$

We assume that the initial temperature of the surface of the cylinder is constant: $T_{0}(l)=T_{*}$. The initial temperature distribution $\mathrm{s}$ given in the form

$$
T_{0}(r)=T_{*}-\frac{l^{2}-r^{2}}{2 l} f_{2}\left(T_{*}\right)
$$

satisfies the consistency conditions (1.5). There we denote $T^{\prime}=\frac{\partial T}{\partial r}$.

In this case $T_{1}(0)=T_{0}(0)=T_{*}-l / 2 f_{2}\left(T_{*}\right)$ and $T_{2}(0)=T_{0}(l)=T_{*}$. Applying those values in the equation (1.1) and taking in account its behavior when $r \rightarrow 0$, we obtain the following conditions equivalent to the (1.5):

$$
\left\{\begin{array}{l}
T_{1}(0)=T_{*}-\frac{l}{2} f_{2}\left(T_{*}\right) \\
T_{2}(0)=T_{*} \\
\dot{T}_{1}(0)=\frac{2}{l} f_{2}\left(T_{*}\right)+F\left(T_{*}-\frac{l}{2} f_{2}\left(T_{*}\right)\right) \\
\dot{T}_{2}(0)=\frac{2}{l} f_{2}\left(T_{*}\right)+F\left(T_{*}\right)
\end{array}\right.
$$


where $\dot{T}=\frac{\partial T}{\partial t}$.

\section{FINITE VOLUME METHOD FOR TWO-POINT SCHEME}

We use the method of finite volumes $[1 ; 2]$ for the approximation of the differential problem (1.1) - (1.4). We consider only two grid points in the $r$ direction: $r_{1}=0, r_{2}=l$. However, considering one of the grid points in the center of the cylinder $\left(r_{1}=0\right)$, complicates the problem: we have to use two different heat transfer equations when building our approximation scheme (remember the behavior of the equation (1.1) when $r \rightarrow 0$ ). Therefore we introduce the small value $\varepsilon>0$, and build our initial approximation considering $r_{1}=\varepsilon$.

We rewrite the equation (1.1) in the form

$$
r(\dot{T}-F(T))=\left(r T^{\prime}\right)^{\prime} .
$$

We integrate the differential equation (2.1) from $\varepsilon$ to $r=l / 2$, thus obtaining the integral form of the conservation law within the interval $r \in(\varepsilon, l / 2)$ :

$$
W_{0.5}-W_{\varepsilon}=\int_{\varepsilon}^{l / 2} r G(t, r) \mathrm{d} r
$$

where $W(t, r)=r T^{\prime}$ is the generalized flux-function and we use notation $W_{0.5}=W(t, l / 2), W_{\varepsilon}=W(t, \varepsilon), G(t, r)=\dot{T}-F(T)$.

By integrating the equation (2.1) from $r=l / 2$ to $r \in(\varepsilon, l)$ and then from $\varepsilon$ to $r_{2}$, we obtain

$$
T_{2}-T_{\varepsilon}=\ln \frac{l}{\varepsilon} W_{0.5}+\int_{\varepsilon}^{l} \frac{\mathrm{d} r}{r} \int_{l / 2}^{r} \xi G(t, \xi) \mathrm{d} \xi,
$$

where $T_{\varepsilon}=T(t, \varepsilon)$.

Expressing $W_{0.5}$ and applying it to (2.2), we obtain the 2-point difference equation :

$$
T_{2}-T_{\varepsilon}-\ln \frac{l}{\varepsilon} W_{\varepsilon}=\ln \frac{l}{\varepsilon} \int_{\varepsilon}^{l / 2} r G(t, r) \mathrm{d} r+\int_{\varepsilon}^{l} \frac{\mathrm{d} r}{r} \int_{l / 2}^{r} \xi G(t, \xi) \mathrm{d} \xi .
$$

The right-hand side integral in this expression can be easily evaluated by changing the integration order, and thus we obtain the difference equation

$$
T_{2}-T_{\varepsilon}-\ln \frac{l}{\varepsilon} W_{\varepsilon}=\int_{\varepsilon}^{l} r \ln \frac{l}{r} G(t, r) \mathrm{d} r .
$$


Assuming that the right-hand side integral converges when $\varepsilon \rightarrow 0$, and taking in account that $T_{\varepsilon} \rightarrow T_{1}$ and from the boundary condition (1.2) $\ln \frac{l}{\varepsilon} W_{\varepsilon} \rightarrow 0$ when $\varepsilon \rightarrow 0$, we obtain the 2 -point difference equation associated with the grid point $r_{1}$ :

$$
T_{2}-T_{1}=\int_{0}^{l} r \ln \frac{l}{r} G(t, r) \mathrm{d} r \equiv R_{1} .
$$

Now we should obtain the difference equation associated with the grid point $r_{2}$. This is the point on the surface of the cylinder, therefore we can ignore the behavior of the equation (1.1) in the center of the cylinder.

We integrate the equation (2.1) within the whole domain $r \in(0, l)$, and obtain the integral form of the conservation law within this interval:

$$
W_{2}-W_{1}=\int_{0}^{l} r G(t, r) \mathrm{d} r
$$

where $W_{2}=W(t, l), W_{1}=W(t, 0)$

From the boundary conditions (1.2) and (1.3) it follows that, $W_{1}=\left.r T^{\prime}\right|_{r=0}=$ $0, W_{2}=\left.r T^{\prime}\right|_{r=l}=l f_{2}\left(T_{2}\right)$. Therefore from (2.4) we obtain the equation associated with the grid point $r_{2}$ :

$$
l f_{2}\left(T_{2}\right)=\int_{0}^{l} r G(t, r) \mathrm{d} r \equiv R_{2}
$$

The difference scheme $(2.3),(2.5)$ is exact. The right-hand side integrals can not be calculated exactly, therefore they need to be approximated.

\section{APPROXIMATION OF INTEGRALS}

We use the quadrature rule of interpolating type for both the integrals $R_{1}$ and $R_{2}$, considering only two-point integration formulae involving points $r_{1}=0$ and $r_{2}=l$. There, many of different approximation methods can be used: involving only function $G$, involving first order derivative of $G$, second order derivative of $G$ etc. We will show the one involving second order derivatives of function $G$.

Let us denote $G_{1}=G(t, 0)$ and $G_{2}=G(t, l)$. The the derivatives $G_{1}^{\prime}$, $G_{1}^{\prime \prime}, G_{2}^{\prime}, G_{2}^{\prime \prime}$ can be found using the boundary conditions (1.2), (1.3) and the equation (1.1). There we denote $G^{(n)}=\frac{\partial^{n} G}{\partial r^{n}}$.

Substituting $\xi=r / l$, we move to non-dimensional form and thus have two grid points $\xi=0, \xi=1$. Therefore integrals $R_{1}$ and $R_{2}$ can be expressed with non-dimensional integrals $I_{1}$ and $I_{2}$ as follows:

$$
R_{1}=l I_{1}, I_{1}=-\int_{0}^{1} \xi \ln \xi g(\xi) \mathrm{d} \xi ; \quad R_{2}=l I_{2}, I_{2}=\int_{0}^{1} \xi g(\xi) \mathrm{d} \xi
$$


where $g(\xi)=G(t, \xi l)$. Denoting $g_{1}=g(0)$ and $g_{2}=g(1)$, we approximate the integral $I_{1}$ with the expression

$$
I_{1}=A_{1}^{1} g_{1}+A_{2}^{1} g_{2}+B_{1}^{1} g_{1}^{\prime}+B_{2}^{1} g_{2}^{\prime}+C_{1}^{1} g_{1}^{\prime \prime}+C_{2}^{1} g_{2}^{\prime \prime}+\frac{1}{6 !} E_{0}^{1} g^{(6)}\left(\eta_{1}\right)
$$

where $\eta_{1} \in(0,1)$.

We postulate that this approximation must exactly integrate polynomials with as possible high order. Presuming $g(\xi)=\xi^{j}, j=\overline{0,5}$, and after the calculation of the right-hand and left-hand sides of the approximating expression, we obtain the system of linear algebraic equations in the form

$$
\left(\frac{1}{j+2}\right)^{2}=A_{1}^{1} 0^{j}+A_{2}^{1}+j\left(B_{1}^{1} 0^{j-1}+B_{2}^{1}\right)+j(j-1)\left(C_{1}^{1}+C_{2}^{1}\right), j=\overline{0,5} .
$$

Defining $0^{0} \equiv 1$, this system solves to $A_{1}^{1}=106 / 735, A_{2}^{1}=311 / 2940, B_{1}^{1}=$ $118 / 3675, B_{2}^{1}=-1181 / 44100, C_{1}^{1}=319 / 117600, C_{2}^{1}=1107 / 44100, E_{0}^{1}=$ $-533 / 235260$.

Similarly, approximating the integral $I_{2}$ with the expression

$$
I_{2}=A_{1}^{2} g_{1}+A_{2}^{2} g_{2}+B_{1}^{2} g_{1}^{\prime}+B_{2}^{2} g_{2}^{\prime}+C_{1}^{2} g_{1}^{\prime \prime}+C_{2}^{2} g_{2}^{\prime \prime}+\frac{1}{6 !} E_{0}^{2} g^{(6)}\left(\eta_{2}\right)
$$

where $\eta_{2} \in(0,1)$, and using the same techniques as for the integral $I_{1}$, we obtain the coefficients $A_{1}^{2}=1 / 7, A_{2}^{2}=5 / 14, B_{1}^{2}=4 / 105, B_{2}^{2}=-13 / 210$, $C_{1}^{2}=1 / 280, C_{2}^{2}=1 / 210, E_{0}^{2}=-1 / 280$.

Moving backwards from the non-dimensional integrals to $R_{1}, R_{2}$, one should take in account that $g^{(n)}=l^{n} G^{(n)}$. Then the integrals $R_{1}$ and $R_{2}$ are approximated using the following expressions of Hermitian interpolation:

$$
\begin{aligned}
& R_{1}=l\left[A_{1}^{1} G_{1}+A_{2}^{1} G_{2}+l\left(B_{1}^{1} G_{1}^{\prime}+B_{2}^{1} G_{2}^{\prime}\right)+l^{2}\left(C_{1}^{1} g_{1}^{\prime \prime}+C_{2}^{1} g_{2}^{\prime \prime}\right)+r_{6_{1}}\right], \\
& R_{2}=l\left[A_{1}^{2} G_{1}+A_{2}^{2} G_{2}+l\left(B_{1}^{2} G_{1}^{\prime}+B_{2}^{2} G_{2}^{\prime}\right)+l^{2}\left(C_{1}^{2} g_{1}^{\prime \prime}+C_{2}^{2} g_{2}^{\prime \prime}\right)+r_{6_{2}}\right],
\end{aligned}
$$

where the truncation terms are

$$
r_{6_{1}}=\frac{l^{6}}{169387200} \frac{\partial^{6} G\left(t, \tilde{\eta}_{1}\right)}{\partial r^{6}}, r_{6_{2}}=\frac{l^{6}}{201600} \frac{\partial^{6} G\left(t, \tilde{\eta}_{2}\right)}{\partial r^{6}}, \tilde{\eta}_{1,2} \in(0, l) .
$$

\section{SYSTEM OF ODES FOR TWO-POINT SCHEME}

Using the difference equations (2.3) and (2.5), and the right-hand side integrals' approximations (3.1), (3.2) with neglected error terms $r_{6_{1,2}}$, the approximate numerical solution for the temperatures in the center of the cylinder $T_{1}(t)$ and on the surface of the cylinder $T_{2}(t)$ at every time step $t>0$ can be 
found by solving the following stiff system of two nonlinear ODEs with initial conditions (1.6):

$$
\left\{\begin{array}{l}
a_{1}^{1} \ddot{T}_{1}+a_{2}^{1} \ddot{T}_{2}+b_{1}^{1} \dot{T}_{1}+b_{2}^{1} \dot{T}_{2}=c_{1} \\
a_{1}^{2} \ddot{T}_{1}+a_{2}^{2} \ddot{T}_{2}+b_{1}^{2} \dot{T}_{1}+b_{2}^{2} \dot{T}_{2}=c_{2}
\end{array}\right.
$$

where the coefficients are

$$
\begin{aligned}
& a_{1}^{1}=\frac{319}{235200} l^{3}, \quad a_{2}^{1}=\frac{107}{44100} l^{3}, \quad a_{1}^{2}=\frac{1}{560} l^{3}, \quad a_{2}^{2}=\frac{1}{210} l^{3}, \\
& b_{1}^{1}=l\left[\frac{106}{735}-l^{2} \frac{319}{235200} F^{\prime}\left(T_{1}\right)\right], \quad b_{1}^{2}=l\left[\frac{1}{7}-l^{2} \frac{1}{560} F^{\prime}\left(T_{1}\right)\right] \\
& b_{2}^{1}=l\left[\frac{311}{2940}-l \frac{46}{1575} f_{2}^{\prime}\left(T_{2}\right)-l^{2} \frac{107}{44100} F^{\prime}\left(T_{2}\right)\right], \\
& b_{2}^{2}=l\left[\frac{5}{14}-l \frac{1}{15} f_{2}^{\prime}\left(T_{2}\right)-l^{2} \frac{1}{210} F^{\prime}\left(T_{2}\right)\right], \\
& c_{1}=\frac{T_{2}-T_{1}}{l}+l\left[\frac{106}{735} F\left(T_{1}\right)+\frac{311}{2940} F\left(T_{2}\right)-l \frac{46}{1575} F^{\prime}\left(T_{2}\right) f_{2}\left(T_{2}\right)\right. \\
& c_{2}=f_{2}\left(T_{2}\right)+l\left[\frac{1}{7} F\left(T_{1}\right)+\frac{5}{14} F\left(T_{2}\right)-l \frac{1}{15} F^{\prime}\left(T_{2}\right) f_{2}\left(T_{2}\right)\right. \\
& \left.\left.\quad+T_{2}\right) f_{2}^{2}\left(T_{2}\right)\right] \\
& \left.\quad F^{\prime \prime} F^{\prime \prime}\left(T_{2}\right) f_{2}^{2}\left(T_{2}\right)\right]
\end{aligned}
$$

There we denote $f_{2}^{\prime}(T)=\frac{\partial f_{2}}{\partial T}$ and $F^{\prime}(T)=\frac{\partial F}{\partial T}$.

\section{NUMERICAL RESULTS}

The numerical solutions of stiff system of ODEs (4.1) are obtained using Maple routines "gear", "mgear" and "lsode", and Mathematica automated routines selection.

The approximate values of $T$ are compared to the values of $T^{*}$ obtained by the Fourier series in the linear case and by the explicit finite difference method with the space step $h=0.02$ and time step $\tau=h^{2} / 6$ in nonlinear case. Comparison of the values of temperature obtained by different numerical methods can be seen in the tables Tab. 1 and Tab. 2. The results of numerical calculations are also presented on figures Fig. 1 and Fig. 2. The control values for the temperatures $T_{1}, T_{2}$ for homogenous equation $(F \equiv 0)$ are computed using (4.1) by: 
Table 1.

Linear case

\begin{tabular}{ccccc}
\hline$t$ & $T_{1}^{*}$ & $T_{2}^{*}$ & $T_{1}$ & $T_{2}$ \\
\hline 0.1 & .1104482 & .4009834 & .1104034 & .4009697 \\
0.2 & .2280236 & .4829622 & .2280027 & .4829517 \\
0.3 & .3318242 & .5530239 & .3318127 & .5530166 \\
0.4 & .4220097 & .6134577 & .4220019 & .6134523 \\
0.5 & .5000886 & .6656946 & .5000827 & .6656905 \\
0.6 & .5676328 & .7108672 & .5676284 & .7108641 \\
0.7 & .6260534 & .7499350 & .6260502 & .7499327 \\
0.8 & .6765808 & .7837238 & .6765786 & .7837222 \\
0.9 & .7202810 & .8129469 & .7202797 & .8129459 \\
1.0 & .7580765 & .8382215 & .7580761 & .8382211 \\
\hline
\end{tabular}

Table 2.

Nonlinear case

\begin{tabular}{ccccc}
\hline$t$ & $T_{1}^{*}$ & $T_{2}^{*}$ & $T_{1}$ & $T_{2}$ \\
\hline 0.2 & .270010 & .416660 & .270009 & .416659 \\
0.4 & .386560 & .527399 & .386557 & .527388 \\
0.6 & .497798 & .628336 & .497788 & .628316 \\
0.8 & .600100 & .715880 & .600082 & .715851 \\
1.0 & .690086 & .788060 & .690059 & .788024 \\
1.2 & .765647 & .844957 & .765613 & .844919 \\
1.4 & .826416 & .888230 & .826380 & .888190 \\
1.6 & .873533 & .920264 & .873498 & .920232 \\
1.8 & .909019 & .943541 & .908986 & .943513 \\
2.0 & .935160 & .960229 & .935131 & .960206 \\
\hline
\end{tabular}

1. In linear case: $T_{*}=0.3, B_{2}=B=0.9, B i_{2}=0$ at the moments of dimensionless time $t_{i}=0.1 \times i, i=\overline{1,10}$;

2. In nonlinear case: $T_{*}=0.3, B i_{2}=B i=0.3, B_{2}=0$, at the time moments $t_{i}=0.2 \times i, i=\overline{1,10}$

Comparing the numerical results, it is visible that the method (4.1) is accurate in average up to $4^{\text {th }}$ decimal place. In some cases its accuracy is up to $5^{t h}-6^{t h}$ decimal place. 


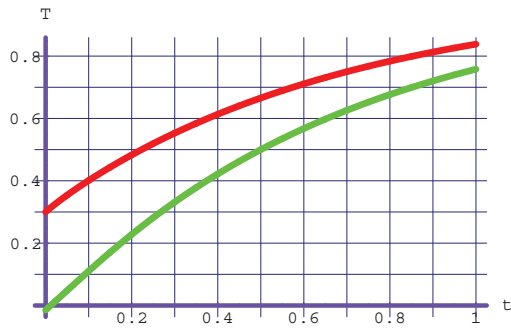

Figure 1. Linear case (darkest curve $\left.-T_{1}\right)$

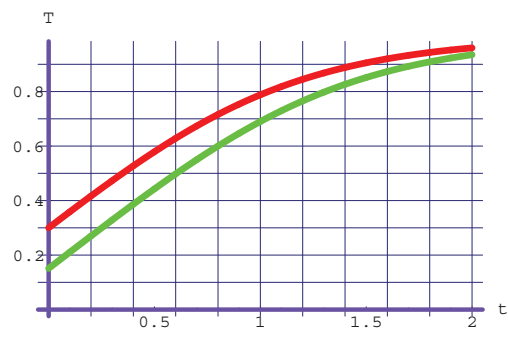

Figure 2. Nonlinear case (darkest curve $\left.-T_{1}\right)$

\section{REFERENCES}

[1] H. Kalis. Finite-difference scheme for solving some heat transfer problems with convection in multilayer media. In: Proc. of the 2nd international conference "Finitedifference methods: theory and applications", 2, Minsk, Belarus, 1998, Finite-difference scheme for solving some heat transfer problems with convection in multilayer media, $1998,50-55$.

[2] H. Kalis, A. Lasis. Article in proceedings. In: Proc. of the International Colloquium "Modelling for Saving Resources", Riga, Latvia, 2001, Effective Methods for Calculation of Heat Losses in Plate, 2001, $204-209$.

[3] K. W. Morton. Numerical solutions for convection-diffusion problems. Oxford, UK, Chapman \& Hall, London, Inc., 1996.

\section{Apie vieną simetrinès šilumos laidumo lygties sprendimo algoritmą}

H. Kalis, A. Lasis

Naudojantis baigtinių tūrių metodu sudaryta tiksli schema, susiejanti sprendinio reikšmes srities krašte ir simetrijos taške. Gautoji lygčių sistema aproksimuojama skaitinio integravimo formulemis ir sprendžiamas pradinis dviejų diferencialinių lygčių sistemos uždavinys. Pateikti skaitinio eksperimento rezultatai. 